\title{
Article
}

\section{Personalisation, Participation and Care}

\author{
Powell, Jason
}

Available at https://clok.uclan.ac.uk/5429/

Powell, Jason orcid iconORCID: 0000-0002-9828-0877 (2011) Personalisation, Participation and Care. British Journal of Health Care Management, 17 (4). pp. 157-164. ISSN 1358-0574

It is advisable to refer to the publisher's version if you intend to cite from the work.

For more information about UCLan's research in this area go to http://www.uclan.ac.uk/researchgroups/ and search for < name of research Group>.

For information about Research generally at UCLan please go to http://www.uclan.ac.uk/research/

All outputs in CLoK are protected by Intellectual Property Rights law, including Copyright law. Copyright, IPR and Moral Rights for the works on this site are retained by the individual authors and/or other copyright owners. Terms and conditions for use of this material are defined in the policies page.

\section{CLoK}

Central Lancashire online Knowledge www.clok.uclan.ac.uk

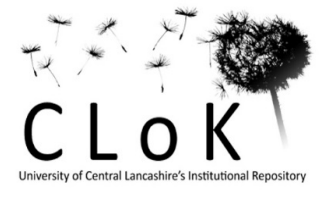




\section{Personalisation, participation and

\begin{abstract}
Personalisation services are developing in England as a social policy response to user demands for more tailored, effective and flexible forms of health and social care support. Across England and Wales, this process is being implemented under the personalization which is also seen as a vehicle for promoting service user rights through increasing participation, empowerment and control while also promoting self-restraint by having users manage the costs of their health and social care. This paper reviews the existing research evidence for personalization, albeit limited, and identifies themes for future research.
\end{abstract}

Personalisation in social care is linked to both the principle and process that every adult who receives support, whether provided by statutory services or funded by them, will have choice and control over the shape of that support in all care settings. This adult social care policy agenda is firmly focused on the development of personalisation of support. This has been repeatedly stated in key policy documents including Improving the Life Chances of Disabled People (published by former Prime Minister's Tony Blair's Strategy Unit in 2005 whilst he was Prime Minister), and the 2006 Community Services White Paper, Our Health, Our Care, Our Say, which announced the piloting of Personal Budgets. Personalisation had its early beginnings in Direct Payments (introduced in 1997 when New Labour came to power), whereby people who are eligible for social care can choose to receive 'cash for care' in lieu of services.

Despite repeated efforts to encourage takeup, and extension of the legislation to include further groups of people within eligibility, direct payment expenditure still accounts for only $1 \%$ of local authority spending on social care. Personal Budgets are being piloted in across English localities. Personal Budgets bring together a range of different funding streams-in addition to social care expenditure-to support independent living. The model for personal budgets was largely derived from work developed by In Control that instigated self-directed support for people with learning disabilities and is engaged in supporting personalisation developments in more than 90 local authorities. Personal Budgets are central to the aim of 'modernising' social care policy and practice in England. They build on the experiences of direct payments and In Control and are intended to offer new opportunities for personalised social care. Its overall aim is for social care service users to have control over how money allocated to their care is spent. It includes within its remit direct payments, Personal Budgets, userled services and self-directed support. Selfassessment is a cornerstone of personalisation that gives service users the opportunity to assess their own care and support needs and decide how their Personal Budgets are spent. This is a process transforming social care. At the same time, the coalition government in 2011 have spoken of the importance of personalization in budget devolvement as most important issue in social care.

\section{Communities}

The traditional focus for social policy has been the role of the state and its effectiveness in the re-distribution of wealth and promotion of social justice for individuals and groups (Blakemore and Giggs 2007). However, the
Jason Powell is Reader in Sociology \& Social Policy, The University of Liverpool

Email: J.L.Powell@ liverpool.ac.uk

Submitted for peer review 22 September 2010; accepted for publication 4 January 2011 
The personalization agenda offers an opportunity to make social care (and other services) more responsive and flexible, so that it is actually doing what people who use budgets and services want and need

later part of the twentieth century and first part of the twenty-first century has seen a recasting of that relationship away from state directed resource allocation to user controlled support with the UK borrowing from the North American consumer led schemes such as Cash and Counseling (Glendenning et al, 2008; Simon-Rusinowitz et al, 2000, 2002; Doty et al. 2007) and northern European examples such as those in the Netherlands, France, Austria and Germany (Wiener et al, 2003; Ungerson and Yeandle, 2006; Kreimer, 2006; Da Roit and Le Bihan, 2008; Boxall et al, 2009). Consequentially personalization and consumer led support has become entrenched as a new language of responsibility in western culture regarding social welfare (Dittrich, 2009) providing new debates about how best to achieve the balance between civil liberties and self-constraint. Put simply personalization, using the language of sustainability namely, the effective use of resources, empowerment, participation, control, choice and human rights (Lundsgaard 2005), re-casts the focus for health and social support onto the individual and away from the state. Users of welfare services are now reinvented as welfare citizens with responsibility for providing to meet their own needs from a 'personalized' individual budget while parallel processes of risk management and safeguarding protect the state from unnecessary exposure (Manthorpe et al, 2009). Using the UK as a case study, this paper will shed light on wider contemporary trends in social policy in general and personal support in particular in western society.

\section{Personalisation and modern societies}

But is this too simplistic a conceptualization? Why and how is personalization relevant to social policy and modern society? How is it researched? How is personalization reconciled in a formidable structural climate of decreasing public resources and the globalization of health and social care provision? This is not just a global economic recession but one of which affects all nation states. Many of these questions can be connected to why personalization services are needed, what is provided and how it is coordinated. The aim of the transformation is to move to personalization in local authority social care provision and to enable the roll out of personal budgets. The personalization agenda offers an opportunity to make social care (and other services) more responsive and flexible so that it is actually doing what people who use budgets and services want and need, rather than being constrained in rigid task and time specifications (Samuel, 2008; Dittrich, 2009).

Personalization is inextricably linked to the process-every person who receives support, whether provided by statutory services or funded by themselves, will have choice and control over the shape of that support in all care settings (Individual Budgets Evaluation Report [IBSEN report], Glendenning et al. 2008). Carr (2008) suggests its overall aim is for social care service users to have control over how money allocated 
to their care is spent. It includes within its remit direct payments, individual budgets, personal budgets, user-led services and self-directed support (Glendenning et al. 2008). Selfassessment is the cornerstone of personalization. It gives service users the opportunity to assess their own care and support needs and decide how their individual budgets are spent while at the same time providing the dynamic for transforming social care (Carr 2008). In circumstances where the service user has limited capacity to either engage in self-assessment or direct their support, a range of possibilities arise such as, family and friends, community based organizations, community based advocacy groups, brokers and agency staff (SCIE, 2007). These in turn, highlight a set of relationships compatible with the new UK administration's focus on the 'Big Society'. However, it is also prudent to note the persistence of a moral undertone as people with substance and alcohol issues tend to be excluded from using individual budgets, as are those leaving custody.

\section{Exploring personalization}

A word of caution however; overall, it is fair to say that the evidence base in relation to the critical success factors of personalization is extremely scarce (Rabiee and Moran, 2006; Moran, 2006; Glendenning et al, 2008). This also means that it is very difficult to bring evidence together in any cumulative sense to gain an impression of the overall or aggregate impact of personalization. A key point to state is that the available literature is on what the implications would be rather than what the implications evidentially are. There have been scarce longitudinal research designs (Glendenning et al, 2008), in which interventions and their beneficial/dystopian effects on IB can be studied over time (Carr 2008); or evaluation designs, for example where ostensibly similar interventions or the work of comparable agencies are undertaken in different settings as the process is only starting to unfold (Moran, 2006; Glendenning et al, 2008). Nevertheless, it is easy to see the attractions of personalization in policy terms as governments look to distance themselves from decisions over the shape of welfare, how it should be delivered, who delivers and at what quality.

(ii) tailoring support to people's individual needs; (iii) recognising and supporting carers in their role, while enabling them to maintain a life beyond their caring responsibilities (HM Government, 2008); (iv) access to universal community services and resources-a 'total system' response; (v) and early intervention and prevention, so that people are supported early on and in a way that's right for them.

\section{Public policy, community and personalization}

As noted earlier, Individual Budgets (IBs) are central to the aim of 'modernizing' social care policy and practice in England (Glendenning et al, 2008). They build on the experiences of direct payments and In Control and are intended to offer new opportunities for personalized social care. Since the 1980 s there has been growing interest among policy makers and service users alike in England in developing ways that enable adults who need support and help with day-to-day activities to exercise choice and control over that help (Powell, 2005). Growing dissatisfaction has been articulated, particularly by working disabled people, about the inflexibility and unreliability of directly provided social care services. These have been argued to create dependency rather than promoting independence and impede disabled people from enjoying full citizenship rights (Dowson and Grieg, 2009). Instead, disabled people have argued for the right to exercise choice and 
control over their lives by having control over the support they need to live independently. This, they have argued, can be achieved by giving them the resources with which to purchase and organize their own support in place of services provided in-kind (Samuel, 2008).

A rather different set of policies have reflected the attempts of successive governments to reduce the control of social care service providers over the composition, timing and flexibility of services and make providers more responsive to the circumstances of individual service users. Thus the 1993 community care reforms made front-line care managers responsible for purchasing individualized 'packages' of services from a range of different providers, tailored to meet individual needs and preferences (Powell, 2005). At that time, the position of monopolistic authority service providers was challenged by the active encouragement of a 'mixed economy' of social care services, funded by local authorities (and increasingly also by individuals funding their own care entirely from their own private resources), but provided by a range of charitable and for-profit organizations (Powell, 2009; Gilbert and Powell, 2010). More recently, policy commentators have argued for the active involvement of users in the co-production of services as this is seen as a means to introduce new incentives for social and health care providers to respond to individual demands; and new incentives for service users to optimize how the resources under their control are used in order to increase cost-effectiveness. This has been repeatedly stated in key policy documents including Improving the Life Chances of Disabled People (published by the Prime Minister's Strategy Unit in 2005), and the 2006 Community Services White Paper, Our Health, Our Care, Our Say which announced the piloting of IBs. The current model for IBs was largely derived from work developed by In Control that pioneered self-directed support for people with learning disabilities and is engaged in supporting personalization developments in more than 90 local authorities (Glendenning et al. 2008).

The intention was to build on experiences with two pre-existing schemes: direct payments (where individuals eligible for social care support receive cash payments in lieu of direct service provision) and the pioneering IBs. The move towards self directed support involves comprehensive change: self-directed support is to become the core way of delivering care and support to service users. Implementing selfdirected support is as much about changing cultures as it is about changing systems (Gilbert and Powell, 2010).

\section{Personalization and research themes}

In order to trace the research themes that emanate from initial experiences of personalization, there is a need to trace the key findings. The ISBEN report (Glendenning et al, 2008) provided a national evaluation of individual budget pilots that have implications for service users, professionals and policy makers. People receiving an IB were significantly more likely to report feeling in control of their daily lives, welcoming the support obtained and how it was delivered, compared to those receiving conventional social care services. However, there were differences between groups.

Mental health service users reported significantly higher quality of life

- Physically disabled adults reported receiving higher quality care and were more satisfied with the help they received

- People with learning disabilities were more 
likely to feel they had control over their daily lives

- Older people reported lower psychological well-being with IBs, perhaps because they felt the processes of planning and managing their own support were burdens

- People who had higher value IBs had better social care outcomesbut so did people receiving higher value conventional services. Overall, holding an IB was associated with better social care outcomes, including higher perceived levels of control, but not with overall psychological well-being in all groups.

Other key findings in the IBSEN report are noted below:

(i) Costs and cost effectiveness

The average weekly cost of an IB was $£ 280$, compared to $£_{300}$ for people receiving conventional social care

- Costs were lowest for mental health service users (average $£ 150$ per week); middling for older people (£230) and physically disabled people (£310); and highest for people with learning disabilities ( $£_{360}$ )

- The costs of IBs were higher for people with greater needs, whether because of problems with daily living activities or cognitive impairments

- Costs were lower for people living with a family carer and those in paid work. IB holders also reported higher use of health services; and more contact with a social worker/care coordinator, reflecting the demands of support planning

- IBs were cost effective for mental health service users and physically disabled people with respect to both social care and psychological well-being outcomes

- For people with learning disabilities, IBs were cost-effective with respect only to social care. For older people, there was no difference in social care outcomes, but standard care arrangements remained slightly more costeffective and people receiving these felt happier.

ii) Eligibility, assessment and resource allocation

- Formal eligibility criteria for social care support remained unchanged in the pilots, but care coordinators took other factors into account when offering IBs such as an individual's ability and willingness to make changes, manage money or understand new processes

- Assessment processes did not necessarily change greatly, although there were greater emphases on self-assessment and outcomes

- In most pilot sites, the sum of money allocated was determined through a Resource Allocation System (RAS). This itemised the help needed by an individual and resulted in a score that translated into a sum of money which equated with the Individual Budget.

(iii) Planning support arrangements with the IB

Deciding how to use an IB was challenging for service users

- Care managers helped individuals to set priorities and identify potential ways of meeting them. Support planning was often judged to be person-focused and accessible

- However, some concerns were raised over the amount and complexity of paperwork and the general slowness of the support planning process. External support planning organizations or advocates were sometimes involved.

- Social care staff experienced major shifts in their roles and responsibilities. Some welcomed these, though others felt their skills were being eroded. Supervision and training in implementing the new IB 
approach were considered essential.

(iv) Integrating funding streams

IBs were expected to include money from several funding streams to enhance flexibility and choice. Pilot site senior managers were enthusiastic about this, but gains were very limited. Barriers included incompatible eligibility criteria; legal and other restrictions on how resources could be used; and poor engagement between central and local government agencies.

- Integrating into IBs the assessment, resource allocation and review processes for other funding streams was thought by IB managers to have been most successful in respect of Supporting People.

The IBSEN report also highlighted some difficulties. It was noted that implementation had been easiest for people with physical and/or sensory impairment, whilst extending the pilot to older people had been slightly more problematic. There were difficulties for people with learning disabilities and widespread difficulties were reported in relation to people with mental health problems. Examples were also cited of financial abuse and deception regarding levels of need. Other concerns were expressed around the costs and complexities of implementing IBs alongside traditional resource allocation systems and that meeting the demand for short-notice and unplanned care in a larger IB system would require a considerable change in the organization of staffing.

\section{Future research themes}

It would be useful to consider future research themes in the context of the of the sustainability paradigm. In this sense we have identified three themes:

- Participation, community cohesion, trust and social capital

One of the biggest tests for personalization will be the influence it has on community participation. As noted earlier, central to the whole process is the parallel development of a range of personal networks, community groups, community based advocacy and options for personal support. This fits well with the community focus of the previous UK government and the 'Big Society' vision of the new administration. However, this assumption has been criticized by some commentators on the development of social policy for social care as persisting with a romantic view of community and neighbourhood (Jordan, 2005; Boxall et al, 2009).

Effects on urban and rural infrastructure, social care markets and the workforce One key area that is yet to be studied is the potential differential effects on urban and rural infrastructure. Policy research in the UK is often criticized for having an urban bias and failing to take account of the different dynamics of rural communities especially the notion of distance decay (Giarchi, 1990); a phenomena where the availability of and access to community based services decreases the further one is from large urban areas. This includes general services such as pubs, post offices, shops and the internet as well as more specialized services of social care. Older people are also disproportionately represented in rural areas (CRC 2009). In addition, concerns have been raised about the availability of a workforce to provide the personal assistants essential to the working of personalization as well as anxiety about whether this will lead to the increased marginalization within the labour market of groups that tend to look to this form of employment such as women and ethnic minorities (Jenson and Jacobzone 2000; 
Ungerson 2004; Breda et al. 2006; Fujisawa and Colombo 2009).

-Satisfaction, control, choice, self-esteem and human rights

As noted above there is evidence that different groups have experienced the introduction of personalization differently. Research is needed to identify the circumstances under which individuals from different groups experience the maximum satisfaction from personalization. The concerns expressed by older people for example may disappear over time as people become accustomed to the way it operates and less anxious about the disappearance of familiar services such as day centres. The other issue that under this heading that requires research relates to human rights and protection from abuse. Presently it is possible to identify lines of accountability across health and social care. However the increasing fragmentation of the sector with the myriad of private relationships means that responsibility for training and credentializing workers is becoming more ambiguous and the role of safeguarding (DoH, 2006) evermore complex (Manthorpe et al, 2009).

\section{Conclusion}

The personalization agenda means a major shift in the way social care and individual support providers approach service. This article has illuminated the policy underpinnings of personalization and its relation to substantive issues in self-directed care in communities across England. Importantly, this paper has located personalization through research studies and thematic areas that are crucial as a baseline for measuring the critical success factors of personal budgets. In particular, the themes that emanate from IBSEN report (2008) can be used as benchmarks to measure the effectiveness of the

\section{KEY POINTS}

- Self-assessment is the cornerstone of personalisation

- Services are less state interventionist and practitioner based with more emphasis on service users independence and own choices

- The research base on personalisation and its outcomes for service users is small and patchy

- Personalization needs comparative analysis in urgan and rural areas

pilots of personalization, social care and personal budgets in England, and other western societies moving towards personalization processes in social welfare for their communities. Not only is this important in policy terms, but as crucially in the daily interactions between service users and the world in which they live-personalisation, in theory, is there to help facilitate their independence.

BJHCM

Association of Directors of Social Services (2009) Making progress with Putting People First, self-directed support

Blakemore K, Griggs E (2007) An Introduction to Social Policy [3rd Edition]. Buckingham: Open University Press

Boxall,K, Dowson S, Beresford P (2009) Selling individual budgets, consumer choice and control: Local and global influences on UK social care policy for people with learning disability. Policy and Politics 37(4): 499-515

Breda J, Shoenmaekers D, Van Landeghem C, Claessens D, Geerts J (2006) 'When informal care becomes a paid job: the case of Personal Assistance Budgets in Flanders'. In C Glendinning and PA Kemp (eds), Cash and Care: Policy challenges in the welfare state, Policy Press, Bristol

Carr S (2008) SCIE Report 20: Personalization: a rough guide, London, SCIE

CIFPA (2007) Direct Payments and Individual Budgets: Managing the Finances (2007), Chartered Institute of Public Finance and Accounting in conjunction with 'In Control' supported by Department of Health. London, CIPFA

CRC [Commission for Rural Communities] (2009) Working Together for Older People in Rural Areas. http://ruralcommunities.gov.uk/2009/07/13/workingtogether-for-older-people-in-rural-areas/ (accessed 4 September 2010)

Da Roit B, Le Bihan, B (2008) Cash-for-care schemes in Austria, Italy, France and the Netherlands; effects on family support and care workers, paper presented to Transforming Elderly Care at Local National and Transnational Levels, International Conference, 26 -28 June, Danish National Centrefor Socal Research, Copenhagen.

Department of Health (2000) No Secrets: Guidance on Developing and Implementing

Department of Health (2007) Putting people first-a shared vision and commitment to the transformation of adult 
social care, London

Department of Health (2008) High quality care for all: NHS next stage review final report, London

Dittrich, R (2009) Personalization and the future of adult social care: the views of Hampshire residents, Research, Policy \& Planning 27(1): 3-16

Doty P, Mohoney KJ. and Simon-Rusinowitz, L. S. (2007) Designing the Cash and Counseling Demonstration and Evaluation. Health Services Research 42(1): 378-96

Dowson S, Grieg R (2009) The Emergence of the Independent Support Broker Role. Journal of Integrated Care 17(4): 22-30

Fujisawa R, Colombo F (2009) The Long-Term Care Workforce: Overview and strategies to adapt supply to a growing demand. DELSAIELSNWP2/HEA(2009)1, OECD, Paris

Giarchi G (1900) Distance Decay and Information Deprivation: Health Implications for people in rural isolation. In P Abbott and G Payne (eds.) New Directions in Sociology. London, Routeledge Falmer

Gilbert T, Powell JL (2010) Power and Social Work in the United Kingdom. Journal of Social Work 10(1): 3-23

Glendinning C, Challis D, Fernandez J, Jacobs S et al (2008) Evaluation of the Individual Budgets Pilot Programme: Final Report, Social Policy Research Unit, (York: University of York, 2008) http://php.york.ac.uk/ inst/spru/pubs/1119 / (accessed 4 March 2010)

HM Government (2008) Carers at the Heart of 21stCentury Families and Communities, London: HMSO http://www.dhcarenetworks.org.uk/_library/Resources/ Personalization/Personalization_advice/Making progress_with_PPF_-_self-directed_support_final.pdf (accessed 24 March 2010)

Jenson J, Jacobzone S (2000) Care Allowances for the Frail Elderly and their Impact on Women Care-Givers, DEELSAIELSNWD(2000)2, OECD, Paris

Jordon B (2005) New Labour: Choice and values. Critical Social Policy 25(4): 427-46

Kreimer M (2006) Developments in Austrian care arrangements. in C. Glendinning and P.A. Kemp (eds.), Cash and Care: Policy challenges in the welfare state, Policy Press, Bristol

Leadbeater, C (2008) 'This Time It's Personal', Society, The Guardian, 16.January 2008.

Leadbedder, C (2004) Personalization through Public Participation, Demos: London, HMSO

Lundsgaard J (2005) Consumer Direction and Choice in Long-Term Care for Older Persons including Payments for Informal Care: How can it help improve care outcomes, employment and fiscal sustainability? DELSAlHEAlHWP(2005)1, OECD Health Working Papers 20, OECD, Paris

Manthorpe J, Stevens M, Rapaport J et al (2009) Safeguarding and System Change: Early Perceptions of the English Individual Budgets Pilots-A Quantitative
Study. British Journal of Social Work 39(8): 1465-480

Moran N (2006) Early experiences of implementing individual budgets. York

Nutley S, Walter I, Davies TO (2007) Using evidence: how research can inform public services. Bristol, Policy Press

Powell JL (2005) Aging and Family Policy in the UK. Journal of Sociology and Social Welfare 32(2): 63-75

Powell JL (2009) From 'Trust Society' to the 'Risk Society'? The Case of Aging and Welfare in Europe. Hallym International Journal of Aging 11(1): 65-76

Rabiee P, Moran N (2006) Interviews with early individual budget holders. York, SPRU

Samuel, M (2008) Social Care Experiencing 'Its Most Important Year' Community Care 31 July 2008

Simon-Rusinowitz, LS, Bochniak AM, Mohoney KJ, et al (2000) Implementation issues for consumer directed programmes: A survey of policy experts. Generations 24(1): 34-40

Simon-Rusinowitz LS, Marks LN, Loughlin SM et al (2002) Implementation issues for consumer directed programmes: Competing views of policy experts, consumers and representatives. Journal of Aging and Social Policy 14(3/4): 95-118

Social Care Institute for Excellence [SCIE] (2007) Choice, control and individual budgets: emerging themes. SCIE Research Briefing 20. London: SCIE

Ungerson C (2004) Whose employment and independence? A cross national perspective on 'cash for care' schemes. Ageing and Society 24(2): 189-212

Ungerson C, Yeandle S (2006) Cash for Care in Developed Welfare States. Basingstoke, Palgrave Macmillan

Venables D, Clarkson P, Hughes J et al (2006) Specialist clinical assessment of vulnerable older people: outcomes for carers from a randomised controlled trial. Ageing and Society 26(6): 867-82

Waine B (2003) Regulation and Inspection of Adult Social care-baseline study. Report to the MASC programme. Available at www.masc.bham.ac.uk (accessed 24 March 2011)

Wanless, D. (2002) Securing our future: taking a long-term view. London: H.M.Treasury

Wanless D (2006) Securing Good Care for Older People: taking a long-term view. London: The King's Fund

Weick K (1995) Sensemaking in organisations. London, Sage

Wiener J, Tilly J, Cuellar AE (2003) Consumer-directed Home Care in the Netherlands, England and Germany, AARP Public Policy Institute, Washington DC 
